Published in "American Journal of Physiology -

Regulatory, Integrative and Comparative Physiology 294: R730-R737, 2008"

which should be cited to refer to this work.

\title{
Fructose ingestion acutely elevates blood pressure in healthy young humans
}

\author{
Clive M. Brown, Abdul G. Dulloo, Gayathri Yepuri, and Jean-Pierre Montani \\ Division of Physiology, Department of Medicine, University of Fribourg, Fribourg, Switzerland
}

\begin{abstract}
Brown CM, Dulloo AG, Yepuri G, Montani J-P. Fructose ingestion acutely elevates blood pressure in healthy young humans. Am J Physiol Regul Integr Comp Physiol 294: R730-R737, 2008. First published January 16, 2008; doi:10.1152/ajpregu.00680.2007.Overconsumption of fructose, particularly in the form of soft drinks, is increasingly recognized as a public health concern. The acute cardiovascular responses to ingesting fructose have not, however, been well-studied in humans. In this randomized crossover study, we compared cardiovascular autonomic regulation after ingesting water and drinks containing either glucose or fructose in 15 healthy volunteers (aged 21-33 yr). The total volume of each drink was $500 \mathrm{ml}$, and the sugar content $60 \mathrm{~g}$. For $30 \mathrm{~min}$ before and $2 \mathrm{~h}$ after each drink, we recorded beat-to-beat heart rate, arterial blood pressure, and cardiac output. Energy expenditure was determined on a minute-by-minute basis. Ingesting the fructose drink significantly increased blood pressure, heart rate, and cardiac output but not total peripheral resistance. Glucose ingestion resulted in a significantly greater increase in cardiac output than fructose but no change in blood pressure and a concomitant decrease in total peripheral resistance. Ingesting glucose and fructose, but not water, significantly increased blood pressure variability and decreased cardiovagal baroreflex sensitivity. Energy expenditure increased by a similar amount after glucose and fructose ingestion, but fructose elicited a significantly greater increase in respiratory quotient. These results show that ingestion of glucose and fructose drinks is characterized by specific hemodynamic responses. In particular, fructose ingestion elicits an increase in blood pressure that is probably mediated by an increase in cardiac output without compensatory peripheral vasodilatation.
\end{abstract}

cardiac output; autonomic nervous system; thermogenesis; heart rate variability

THE LAST 30 YEARS have seen a tremendous increase in the consumption of refined sugars in Western diets (27). Carbonated soft drinks supply about one-third of the total daily sugar intake, with fruit drinks contributing a further $10 \%$ (23). Fructose comprises about one-half of the sugar in soft drinks, either bound to glucose as the disaccharide sucrose or as a component of high-fructose corn syrup, which is increasingly used as the sweetener in soft drinks (4). Studies in animals have shown a clear association between sugar intake and the development of hypertension and tachycardia (9). The fructose component seems to be particularly damaging because, in dogs, a diet that is high in fructose, but not one that is high in glucose, leads to hypertension, elevated plasma triglycerides, insulin resistance, and hyperinsulinemia (20). High-fructose diets have also been linked with the development of cardiac hypertrophy (16), reduced baroreflex sensitivity (21), and renal damage (29) in rats. However, the acute effects of fructose ingestion on blood pressure and hemodynamics are unclear.

In humans, ingestion and metabolism of different nutrients elicit hemodynamic responses that are determined to some extent by the type of nutrient (14). The monosaccharides glucose and fructose have contrasting effects on blood flow and sympathetic activity. Infusion of glucose acutely increases muscle nerve sympathetic activity and causes vasodilatation in calf skeletal muscle (37), and oral ingestion of glucose increases splanchnic blood flow (7). In contrast to glucose, fructose does not acutely increase muscle nerve sympathetic nerve activity or cause vasodilatation in skeletal muscle (37) or in the splanchnic circulation (8). There is, however, evidence that fructose ingestion results in increased plasma norepinephrine levels (15). Moreover, fructose seems to stimulate cardiac sympathetic activity because infusion of fructose causes an increase in heart rate that is suppressed during $\beta$-adrenergic blockade (31).

Based on the above findings, we hypothesized that fructose would exert an acute increase in blood pressure via increased sympathetic activity to the heart and subsequent elevation in cardiac output without a peripheral vasodilatory response. Despite the evidence that infusion of glucose and fructose elicits different hemodynamic responses, integrated cardiovascular responses to oral ingestion of these simple sugars have not been well-studied, particularly in the context of soft drinks.

The aim of the present study was to determine, in a randomized crossover study, the cardiovascular and thermogenic responses to oral ingestion of glucose and fructose. We therefore measured oxygen consumption and beat-to-beat heart rate, blood pressure, and cardiac output in response to drinks containing water, glucose, and fructose in a series of healthy, young humans.

\section{MATERIALS AND METHODS}

Fifteen healthy normal-weight volunteers ( 9 male, 6 female), aged 21-33 (mean $24 \pm 1$ ) yr, were recruited by advertisement and paid. The mean height of the males was $176 \pm 2 \mathrm{~cm}$, their weight was $71 \pm$ $3 \mathrm{~kg}$, and their body mass index was $22.9 \pm 0.8 \mathrm{~kg} / \mathrm{m}^{2}$. The mean height of the females was $171 \pm 2 \mathrm{~cm}$, their weight was $59 \pm 2 \mathrm{~kg}$, and their body mass index was $20.1 \pm 0.2 \mathrm{~kg} / \mathrm{m}^{2}$. None of the subjects had any diseases or were taking any medication affecting cardiovascular or autonomic regulation. The participants were requested to avoid alcohol or caffeine for $24 \mathrm{~h}$ and were studied in the morning after an overnight (12-h) fast. Subjects were also asked to empty their bladders immediately before the experiment. Written informed consent was obtained from each participant. The study protocol complied with the Declaration of Helsinki and received local ethics committee approval.

Protocol. All measurements were performed in a temperaturecontrolled $\left(22 \pm 1^{\circ} \mathrm{C}\right)$ quiet laboratory. Every subject attended three separate experimental sessions (each session separated by at least 3 days) according to a randomized crossover design. At each experimental session, the responses to one of three test drinks were measured. The drinks tested were: 1) water, 2) water containing $60 \mathrm{~g}$ 
glucose, and 3) water containing $60 \mathrm{~g}$ fructose. Each drink contained $10 \mathrm{ml}$ lemon juice (to provide a more uniform taste) and was made up to a total of $500 \mathrm{ml}$ by addition of distilled water. The subjects were not told the order of the drinks.

Each subject was studied while sitting in a comfortable armchair. Instruments for cardiovascular monitoring and indirect calorimetry were attached, and the recording started 30-40 min later when the signals had stabilized. After a 30-min baseline period, the subject was given a test drink to consume over a period of $4 \mathrm{~min}$. Cardiovascular and metabolic monitoring was continued for a further $120 \mathrm{~min}$ after the drink.

Noninvasive cardiovascular recordings were performed using a Task Force Monitor (CNSystems, Medizintechnik, Graz, Austria) with data sampled at a rate of $1,000 \mathrm{~Hz}$ (5). Cardiac intervals (and their reciprocal, heart rate) were recorded by electrocardiography. Continuous blood pressure was recorded from the middle finger of the right hand using the vascular unloading technique and was calibrated to oscillometric brachial blood pressure measurements on the contralateral arm. Thoracic impedance was recorded using band electrodes, one placed on the back of the neck and two parallel electrodes placed on the lateral sides of the thorax at the level of the xiphoid process. Cardiac stroke volume was derived on a beat-to-beat basis from the impedance cardiogram.

Respiratory gas exchange was measured by indirect calorimetery using an open-circuit ventilated hood system (Deltatrac monitor, Datex, Helsinki, Finland). Resting energy expenditure and respiratory quotient were derived from the rates of oxygen consumption and carbon dioxide production using the Weir equation (38).

Data analysis. Values of cardiac interval, blood pressure (systolic, mean, and diastolic), cardiac stroke volume, and gaseous exchange parameters were averaged every $15 \mathrm{~min}$ during the baseline period and the 2 -h postdrink period. The pressure-rate double product was calculated as the product of systolic blood pressure and heart rate, whereas cardiac output was computed as the product of stroke volume and heart rate. Total peripheral resistance was calculated as mean blood pressure divided by cardiac output.

Cardiovagal baroreflex sensitivity was determined from spontaneous fluctuations in systolic blood pressure and cardiac interval using the sequence technique (3), which has been shown to give similar results to the gold-standard phenylephrine method (26). Sequences were identified where systolic blood pressure spontaneously increased or decreased by at least $1 \mathrm{mmHg} / \mathrm{beat}$ over at least three consecutive heart beats, and, at the same time, cardiac interval changed by at least $4 \mathrm{~ms} /$ beat in the same direction. For each sequence, linear regression was applied to the values of systolic pressure and the subsequent cardiac interval (zero beat delay), and the baroreceptor sensitivity was taken as the average regression slope for all sequences with a sufficiently high $r^{2}$ value $(\geq 0.85)$

Cardiac interval and blood pressure variabilities were evaluated by power spectral analysis (33). Five-minute data sets were analyzed by Fast-Fourier transformation using a Hamming window. For each dataset, spectral power was obtained in the low-frequency (LF; $0.03-0.15 \mathrm{~Hz})$ and high-frequency $(\mathrm{HF} ; 0.15-0.40 \mathrm{~Hz})$ ranges. Due to their skewed distributions, powers of cardiac interval and blood pressure were analyzed after natural logarithmic transformation.

Statistics. All values are reported as means \pm SE. Statistical analysis was performed by two-way ANOVA for repeated measures with time and treatment (drink type) as within-subject factors using statistical software (Statistix version 8.0; Analytical Software, St. Paul, MN). Where significant differences were found, the effects of each drink over time were analyzed by comparing values at each time point over the postdrink period with the basal values recorded during the 30 min immediately before drinking using Dunnett's test for multiple comparisons. Responses to each drink were then calculated as the mean change from baseline value over the 2-h postdrink period and compared using a one-way repeated-measures ANOVA followed by Newman-Keul's posttest. The level of statistical significance was set as $P<0.05$.

\section{RESULTS}

Cardiovascular responses to the water and sugar drinks. Resting values of the cardiovascular variables were similar during the baseline period for all three drinks (Table 1). Every subject ingested each drink without problems, and none reported nausea or other unpleasant effects.

Figure 1 shows the changes in blood pressure and heart rate after ingesting water, glucose, and fructose. For systolic and diastolic blood pressure, as well as heart rate, there were significant treatment and time effects and treatment $\times$ time interactions (all $P<0.01$ ). After fructose ingestion, systolic and diastolic blood pressure increased significantly $(P<0.01)$, with the response starting within $30 \mathrm{~min}$ of consuming the drink. The fructose-induced elevation in blood pressure was maintained for the entire duration of the postdrink recording, with the systolic blood pressure peaking at $6.2 \pm 0.8 \mathrm{mmHg}$ above baseline. Although blood pressure increased slightly after water drinking, the effect was not significant. Ingestion of the glucose drink also had no significant effects on blood pressure. Heart rate initially decreased $(P<0.01)$ in response to drinking water before returning toward the baseline value. In contrast, ingesting the glucose and fructose drinks both increased heart rate, which was still significantly $(P<0.01)$ elevated at the end of the $2-\mathrm{h}$ postdrink recording period. Although comparison of the responses to different drinks showed that the overall heart rate responses did not differ significantly between ingestion of glucose and fructose, the increase in heart rate over the second hour compared with baseline was significantly greater $(P<0.05)$ after fructose $(+7.2 \pm 0.9$ beats $/ \mathrm{min})$ than after glucose $(+4.0 \pm 0.7$ beats/min) or water $(-0.9 \pm 1.0$ beats $/ \mathrm{min})$ drinking.

The responses of the pressure-rate double product, cardiac output, and total peripheral resistance are shown in Fig. 2. There were significant treatment and time effects and significant treatment $\times$ time interactions for the double product and cardiac output (all $P<0.01$ ). In contrast to water, the double product increased with both glucose and fructose drinks $(P<$ 0.01 ). Comparison of the responses to the drinks (mean change from baseline) showed that the elevation in double product was significantly greater for fructose than for glucose $(P<0.05)$.

Table 1. Baseline data recorded in the $30 \mathrm{~min}$ immediately before ingesting each of the drinks

\begin{tabular}{lccc}
\hline \hline & Water & Glucose & Fructose \\
\hline Systolic blood pressure, $\mathrm{mmHg}$ & $113 \pm 2$ & $112 \pm 2$ & $113 \pm 2$ \\
Mean blood pressure, $\mathrm{mmHg}$ & $85 \pm 1$ & $84 \pm 2$ & $85 \pm 2$ \\
Diastolic blood pressure, $\mathrm{mmHg}$ & $73 \pm 1$ & $72 \pm 2$ & $73 \pm 2$ \\
Heart rate, beats/min & $65 \pm 2$ & $63 \pm 2$ & $66 \pm 2$ \\
Double product, $\mathrm{mmHg} \cdot$ beat $\cdot \mathrm{min}^{-1}$ & $7,346 \pm 200$ & $7,061 \pm 205$ & $7,385 \pm 183$ \\
Stroke volume, $\mathrm{ml}$ & $76 \pm 4$ & $79 \pm 5$ & $76 \pm 4$ \\
Cardiac output, $/ \mathrm{min}$ & $4.87 \pm 0.17$ & $4.93 \pm 0.20$ & $4.91 \pm 0.18$ \\
Total peripheral resistance, & & & \\
$\quad$ mmHg $\cdot 1^{-1} \cdot \min$ & $17.8 \pm 0.7$ & $17.4 \pm 0.7$ & $17.7 \pm 0.8$ \\
Baroreflex sensitivity, $\mathrm{ms} / \mathrm{mmHg}$ & $20.6 \pm 1.9$ & $24.5 \pm 2.9$ & $20.1 \pm 2.5$ \\
Resting oxygen consumption, $\mathrm{ml} / \mathrm{min}$ & $216 \pm 7$ & $214 \pm 8$ & $214 \pm 6$ \\
Resting energy expenditure, $\mathrm{kJ} / \mathrm{min}$ & $4.34 \pm 0.13$ & $4.30 \pm 0.16$ & $4.37 \pm 0.13$ \\
Respiratory quotient & $0.86 \pm 0.02$ & $0.86 \pm 0.01$ & $0.85 \pm 0.02$ \\
\end{tabular}

Data are presented as means $\pm \mathrm{SE}$. 
Fig. 1. Time course of the systolic blood pressure $(\mathrm{SBP} ; A)$, diastolic blood pressure (DBP; $B)$, and heart rate (HR; $C$ ) changes (left) and mean responses (right) to drinking water $(O)$, glucose $(\mathbf{\Delta})$, and fructose ( $\mathbf{\square})$. $* P<0.05$ and $* * P<0.01$, statistically significant differences over time from baseline values (left) and differences between responses to the drinks (right).
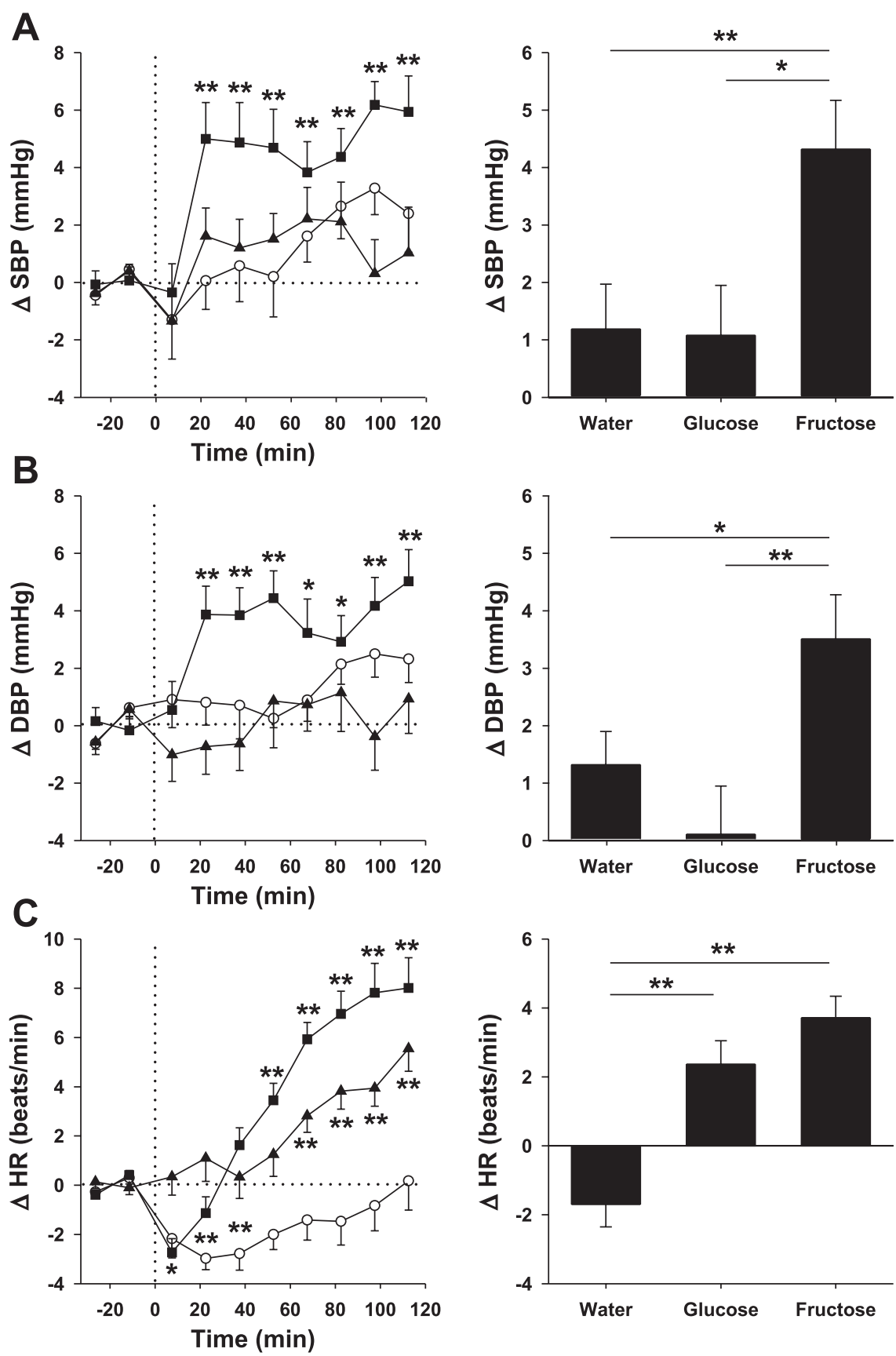

Cardiac output remained stable after the water drink but increased significantly after the glucose and fructose drinks (both $P<0.01)$. Comparison of the responses to the drinks showed that the increase in cardiac output after fructose ingestion was only about one-half of that measured after ingesting glucose $(P<0.05)$. For total peripheral resistance, there was a significant treatment effect $(P<0.01)$ and treatment $\times$ time interaction $(P<0.01)$. Total peripheral resistance decreased significantly after ingesting the glucose drink $(P<0.01)$ but showed no significant change after the water or fructose drinks.

Baroreflex sensitivity and cardiovascular variability. For baroreflex sensitivity, there were significant treatment $(P<$ $0.01)$ and time $(P<0.01)$ effects and a significant treatment $\times$ time interaction $(P<0.01)$. Baroreflex sensitivity (Fig. 3) increased significantly over time after ingesting water $(P<$ $0.01)$ but decreased following ingestion of the glucose $(P<$ $0.05)$ and fructose $(P<0.01)$ drinks. However, comparison of the mean postdrink changes in baroreflex sensitivity showed no significant differences between ingesting glucose and fructose.

Changes in cardiac interval HF and LF power are shown in Fig. 4. There were significant treatment $(P<0.01)$ and time $(P<0.01)$ effects and a treatment $\times$ time interaction $(P<$ $0.01)$ for cardiac interval HF power. Water drinking induced an immediate increase in cardiac interval HF power $(P<0.01)$ that slowly returned toward the basal value. After ingesting glucose, cardiac interval $\mathrm{HF}$ power initially increased $(P<$ 0.01 ) and returned to a level that was slightly, but not signif- 

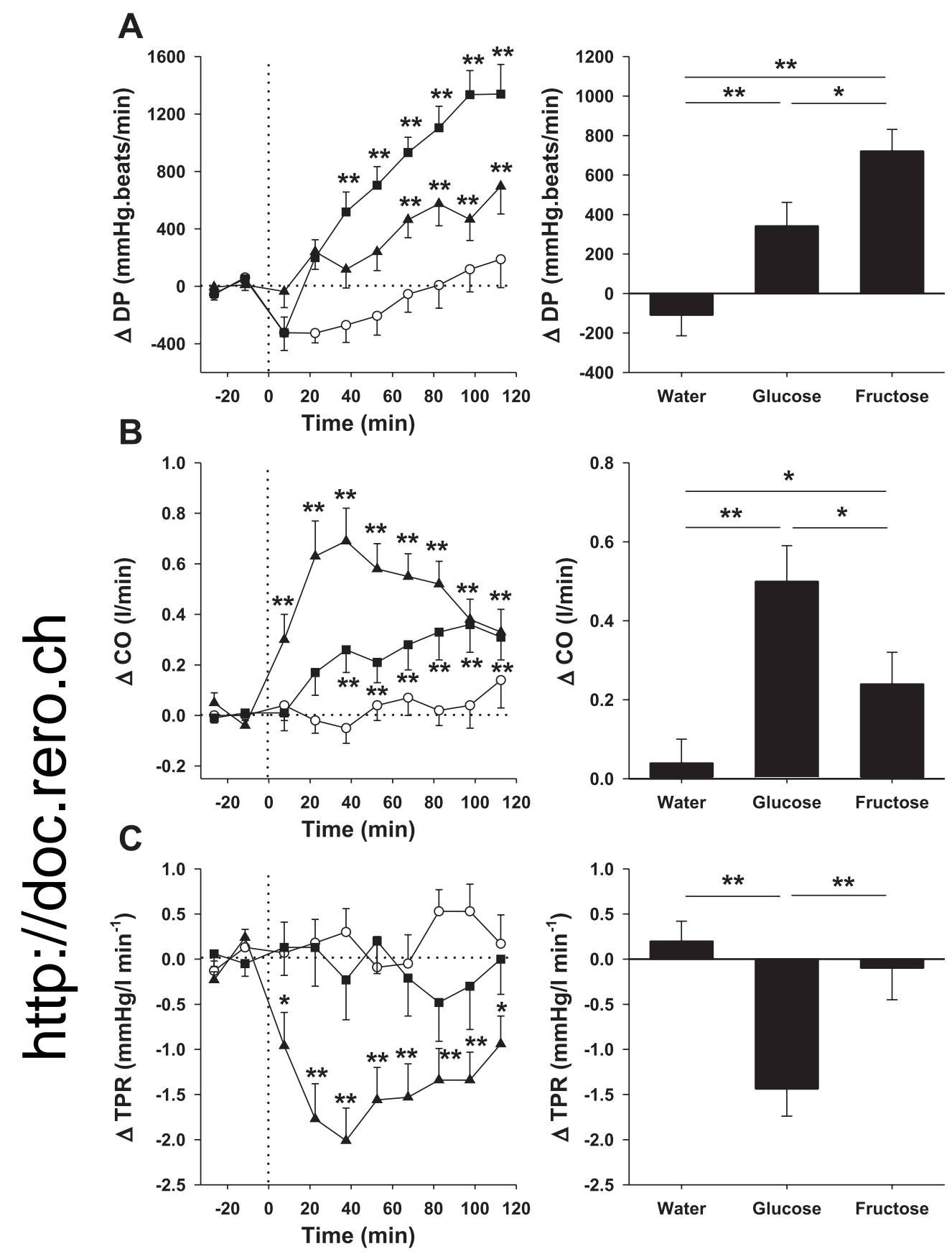

Fig. 2. Time course of the pressure-rate double product (DP; $A)$, cardiac output $(\mathrm{CO} ; B)$, and total peripheral resistance response (TPR; $C$ ) changes (left) and mean responses (right) to drinking water $(\bigcirc)$, glucose $(\mathbf{\Lambda})$, and fructose $(\mathbf{\varpi}) . * P<0.05$ and $* * P<0.01$, statistically significant differences over time from baseline values (left) and differences between responses to the drinks (right).

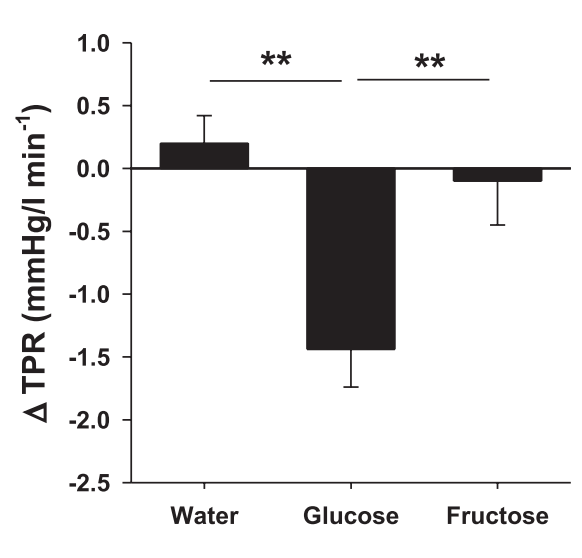

icantly, below the baseline. Fructose ingestion also caused an initial increase in cardiac interval HF power $(P<0.01)$, but at 1 -h after the drink there was a sustained fall in HF power to significantly below the baseline value $(P<0.05)$. For cardiac interval LF power, there was a significant time $(P<0.05)$ effect. Cardiac interval LF power increased significantly after ingesting the glucose and fructose drinks (both $P<0.01$ ) but not after ingesting water.

Figure 5 shows changes in mean arterial blood pressure variability. There were significant time effects $(P<0.01)$ for both LF and HF blood pressure variability. Ingestion of the glucose and fructose drinks resulted in significant increases in $\mathrm{HF}$ and LF blood pressure variability (all $P<0.05$ ), but drinking water had no consistent effects on blood pressure variability.
Gaseous exchange and thermogenic responses. Resting values of oxygen consumption, energy expenditure, and respiratory quotient are shown in Table 1 . Changes in resting energy expenditure and respiratory quotient after the drinks are shown in Fig. 6. There were significant treatment $(P<0.01)$ and time $(P<0.01)$ effects and a treatment $\times$ time interaction $(P<$ $0.01)$ on resting energy expenditure. Ingestion of glucose and fructose, but not water, significantly increased oxygen consumption (both $P<0.01$ ). When responses to the drinks were compared, the average postdrink changes in resting energy expenditure did not differ significantly between glucose and fructose ingestion.

For respiratory quotient, there were significant treatment $(P<0.01)$ and time $(P<0.01)$ effects and a treatment $\times$ time 
Fig. 3. Time course of the changes (left) in baroreflex sensitivity (BRS) and mean responses (right) after drinking water (O), glucose ( $(\mathbf{\Delta})$, and fructose $(\mathbf{\square}) . * P<$ 0.05 and $* * P<0.01$, statistically significant differences over time from baseline values (left) and differences between responses to the drinks (right).
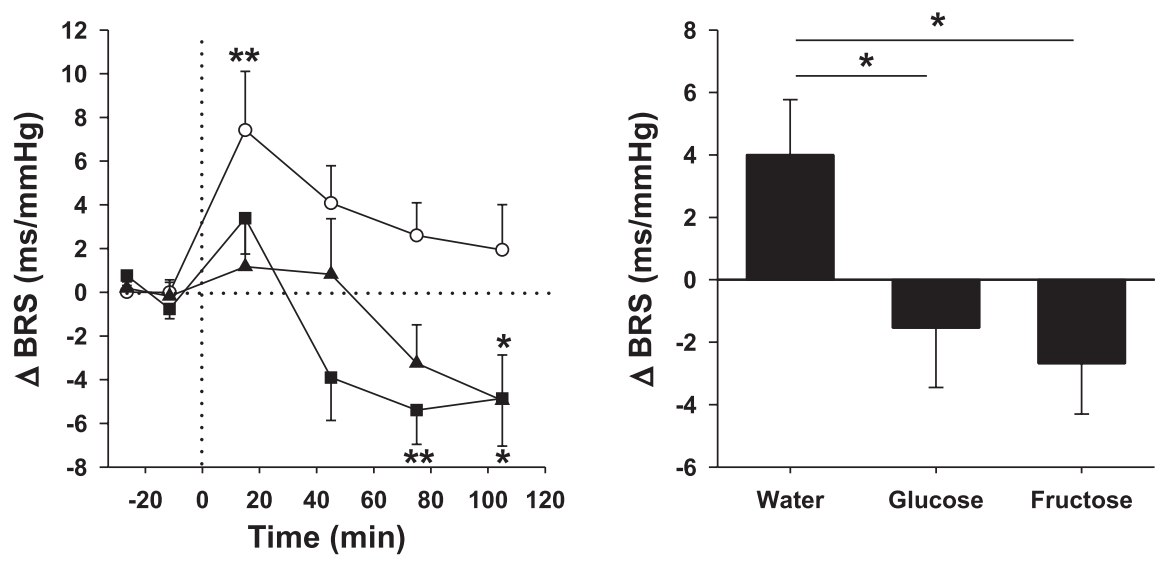

interaction $(P<0.01)$. Ingestion of glucose and fructose significantly increased respiratory quotient $(P<0.01)$, but water had no effect. Comparison of the responses to the drinks showed that the average increase in respiratory quotient after fructose ingestion was more than double that observed after ingesting the glucose drink $(P<0.01)$.

\section{DISCUSSION}

Studies in animals have linked diets that are high in fructose with the onset of hypertension, tachycardia, cardiac hypertrophy, and renal damage $(16,20,29)$. The current study was designed to investigate, in healthy young humans, the acute cardiovascular responses to ingesting drinks containing simple sugars. Although some studies have investigated certain aspects of cardiovascular regulation and regional blood flows in response to glucose and fructose $(8,15,37)$, a particular strength of our study is that we noninvasively and comprehensively determined responses of beat-to-beat blood pressure and cardiac output, as well as autonomic regulation and gaseous exchange in the same set of subjects. A further advantage of our study was that we utilized a crossover design in which every subject was exposed to each of the test drinks.

Our main finding was that oral ingestion of a fructose drink initiated a significant elevation in blood pressure for at least $2 \mathrm{~h}$ after the drink. In contrast, no blood pressure increase was observed after ingesting water or a glucose drink. Compared
Fig. 4. Time course of the changes in high-frequency $(\mathrm{HF})$ power $(A)$ and low-frequency (LF) power $(B)$ of cardiac interval variability (left) and mean responses (right) after drinking water (O), glucose (ム), and fructose (匹). $* P<0.05$ and $* * P<0.01$, statistically significant differences over time from baseline values.
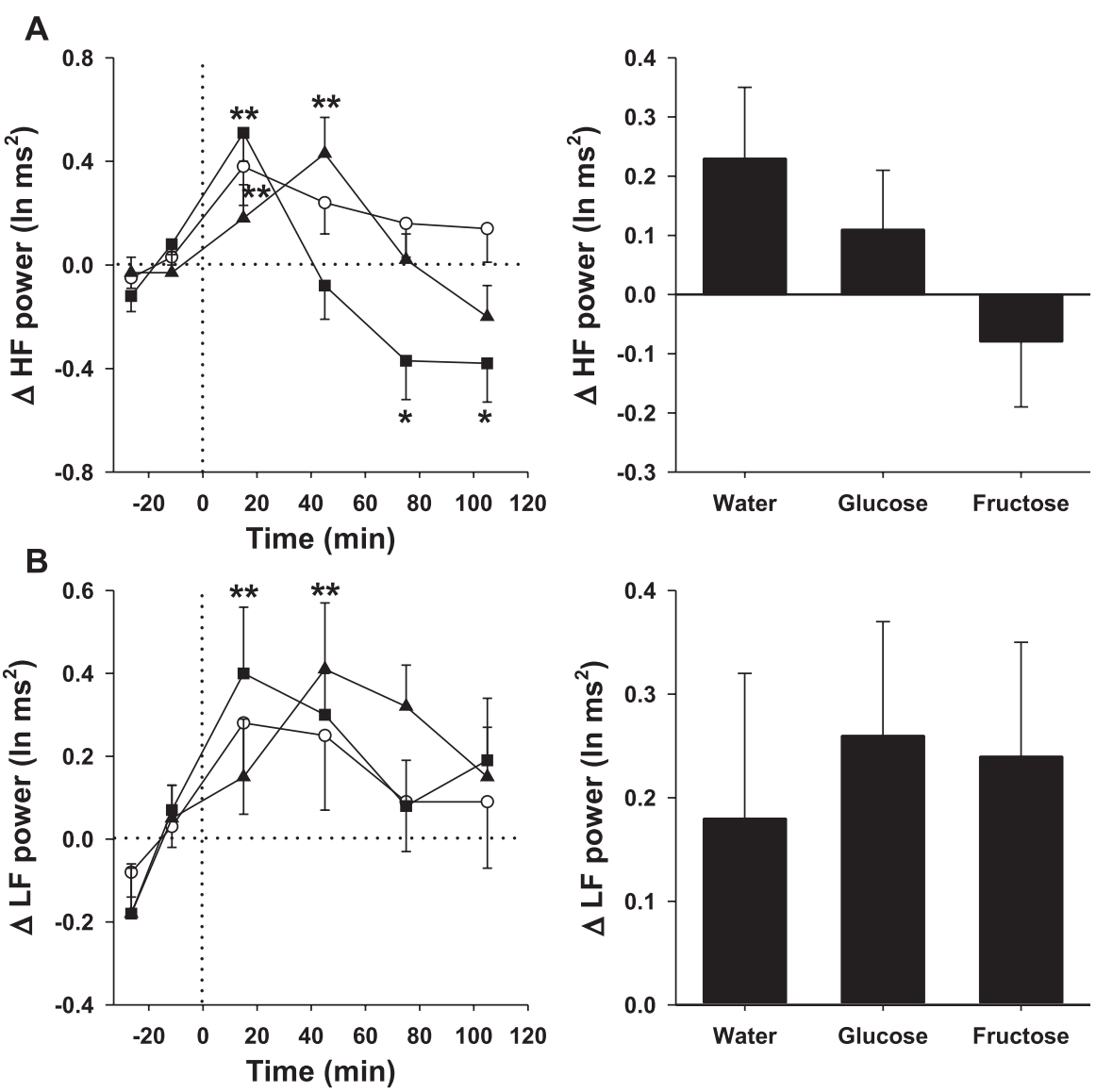

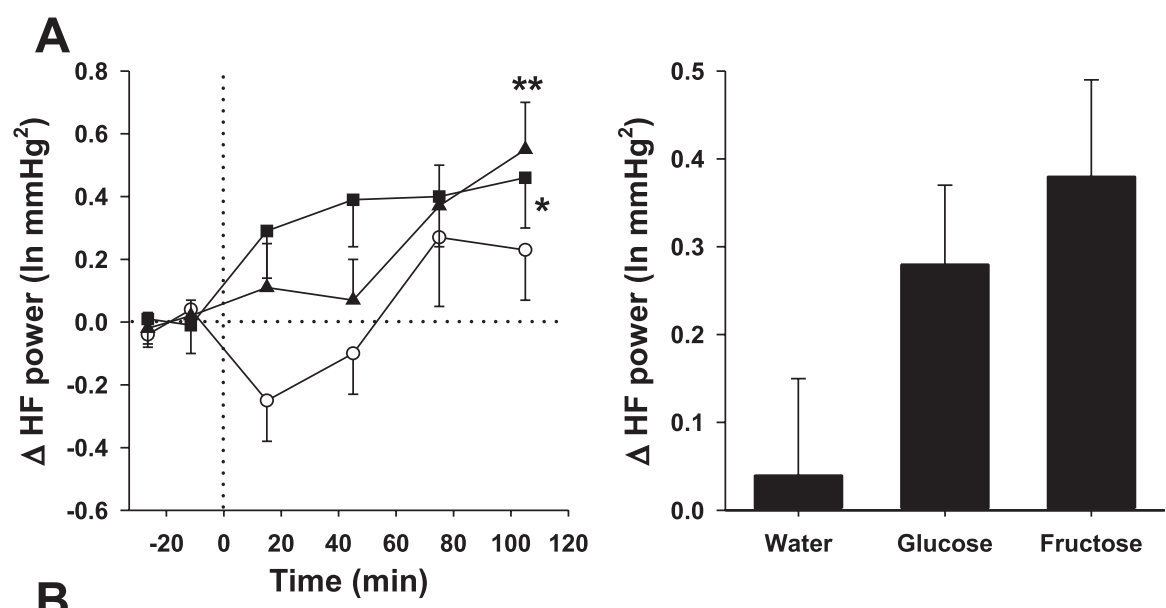

Fig. 5. Time course of the changes in HF power $(A)$ and (B) LF power $(B)$ of mean arterial pressure variability (left) and mean responses (right) after drinking water $(\bigcirc)$, glucose $(\mathbf{\Delta})$, and fructose $(\mathbf{\square})$.
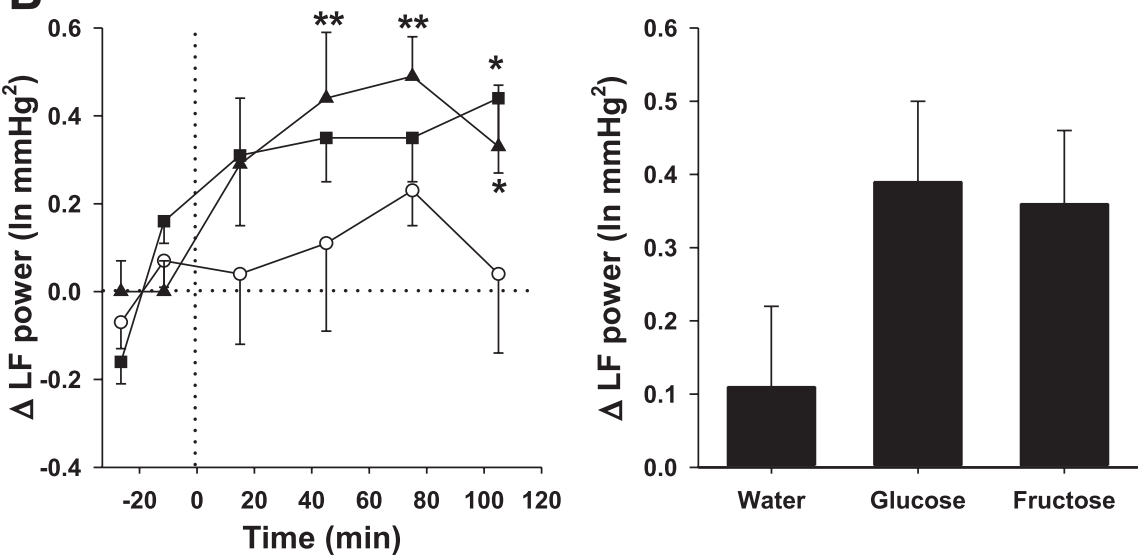
$* P<0.05$ and ${ }^{*} * P<0.01$, statistically significant differences over time from baseline values.

with glucose, ingestion of fructose also resulted in greater increases in heart rate and pressure-rate double product, an index of myocardial oxygen demand $(1,17)$. These results support the concept that ingestion and metabolism of different sugars elicit specific patterns of hemodynamic responses. In particular, the elevated blood pressure and myocardial oxygen demand in response to fructose suggests that oral ingestion of this monosaccharide elicits a moderate cardiovascular load for at least $2 \mathrm{~h}$ after the drink.

The increase in blood pressure in response to ingesting a fructose drink was characterized by gradual increases in heart rate and cardiac output but no compensatory reduction in total peripheral resistance. There was a decrease in the high-frequency component of cardiac interval variability $\sim 1 \mathrm{~h}$ after fructose ingestion, suggesting withdrawal of cardiovagal tone (33). Although interpretation of the low-frequency component of heart rate variability is controversial (19), the augmented low-frequency power that we observed after fructose ingestion is consistent with an elevation in sympathetic tone to the heart (18). Cardiac sympathetic stimulation by fructose is further supported by evidence that the rise in heart rate during fructose infusion is attenuated by $\beta$-adrenoceptor blockade with propranolol (31). Although cardiac output was increased after fructose ingestion, the response was much lower than after glucose ingestion. However, unlike fructose, ingestion of a glucose drink lowered total peripheral resistance. Therefore, glucose ingestion had no net effect on blood pressure, a result that is in line with previous findings $(24,37)$.
The mechanism of the cardiac sympathetic stimulation following ingestion of glucose and fructose remains to be established. Although insulin has a role in elevating cardiac contractility and heart rate (22), this is unlikely to be a factor in the response to fructose ingestion, since, compared with glucose, fructose has negligible effects on insulin secretion $(8,11,12$, $15,28,32,37)$. The cardiac stimulation after ingesting glucose and fructose might be due to factors within the gastrointestinal tract or portal circulation. For example, the liver has a rich autonomic neural innervation, and some evidence suggests the possible existence of hepatic glucose and fructose receptors (30).

The contrasting vascular responses to fructose and glucose ingestion might be explained, at least in part, by the hemodynamic actions of insulin. Physiological elevations of plasma insulin concentration provoke a rise in cardiac output and a reduction in muscle and systemic vascular resistance (2). The relative lack of an insulin response after fructose $(8,11,12,15$, $28,32,37)$ might, at least in part, explain the absence of peripheral vasodilatation. In our study, we did not actually measure insulin concentrations, since we wanted to avoid taking blood samples, which would influence the subtle autonomic responses and possibly interfere with blood pressure regulation after the drinks. However, the insulin responses to ingesting drinks containing glucose and fructose have been well-defined by other studies $(8,11,12,15,28,32,37)$.

Some previous studies have also determined blood pressure responses to ingestion of simple sugars. For example, Visvanathan et al. (35) reported that, in elderly individuals (who 
Fig. 6. Time course of the changes in resting energy expenditure (REE; $A$ ) and respiratory quotient (RQ; $B$ ) (left) and mean responses (right panels) after drinking water $(\bigcirc)$, glucose $(\mathbf{\Lambda})$, and fructose $(\mathbf{\square}) . * P<0.05$ and $* * P<0.01$, statistically significant differences over time from baseline values (left) and differences between responses to the drinks (right).
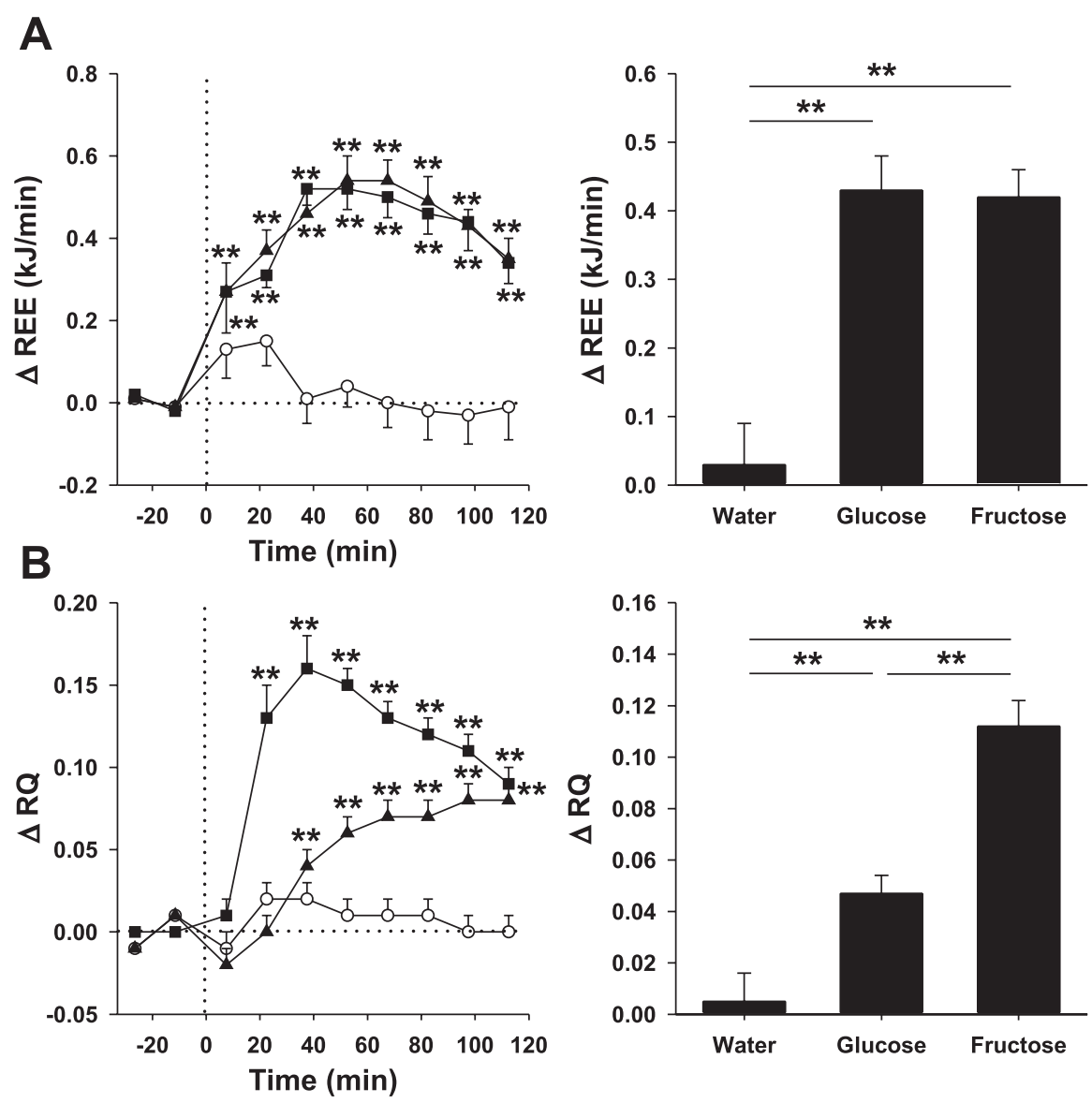

are susceptible to postprandial hypotension), blood pressure decreased after ingesting 50-g loads of sucrose and glucose, whereas fructose ingestion had no effect. A study performed in young subjects showed no change in blood pressure in response to glucose or fructose ingestion (15). However, in that study, there were some methodological differences compared with ours. We recorded continuous (beat-to-beat) blood pressure, whereas, in the previous study (15), an intermittent method was used. Another difference is that our subjects were studied while in a seated position, but, in the previous study (15), the subjects were supine. Our study was also entirely noninvasive to avoid the potential influence of blood sampling on autonomic regulation. Another study demonstrated that intravenous infusion of glucose and fructose had no effects on blood pressure (37). There is, however, evidence that the route of administration (oral vs. intravenous) can influence the physiological responses to monosaccharides (7).

Although ingestion of the glucose drink did not cause an elevation in the mean level of blood pressure, there was a significant increase in blood pressure variability that was also observed in response to the fructose drink. In clinical studies, augmented blood pressure variability has been linked to target organ damage and subsequent development of hypertension, even without changes in the mean level of blood pressure (25). The mechanism for the increase in blood pressure variability after ingesting sugar drinks is unclear but might be related to either an acute vascular endothelial dysfunction, which has previously been reported after glucose ingestion (10), or to the reduced baroreflex sensitivity that we observed in response to the sugar drinks.

Indirect calorimetry confirmed our previous finding that water ingestion has no effect on resting energy expenditure (6). Although the glucose and fructose drinks elevated resting energy expenditure by similar amounts, the increase in respiratory quotient was much greater for the fructose drink than it was for the glucose drink. The higher respiratory quotient after fructose ingestion is consistent with an increased conversion of carbohydrate to fat (13). There is some evidence that acute fructose ingestion favors lipogenesis, detectable within $2-4 \mathrm{~h}$ (11), and that consuming fructose-sweetened beverages with meals potentiates the postprandial elevation in plasma triglycerides in humans (34). The subjects in our study had undergone a 12-h fast before the measurements to avoid potential effects of previous meals. Considering the acute endothelial dysfunction caused by high plasma levels of blood triglycerides (36), it is possible that a prior meal would augment the cardiovascular responses to consuming a drink containing fructose.

\section{Perspectives and Significance}

Our findings demonstrate that, in young healthy individuals, consuming glucose and fructose drinks results in markedly different hemodynamic responses, with fructose stimulating a sustained increase in blood pressure. Although it is difficult to extrapolate acute responses to long-term effects, our results support the concept that diets that include repeated fructose 
loads might contribute, over time, to increased cardiovascular risk.

\section{GRANTS}

This study was supported by grants from the Swiss National Science Foundation (Project no. 3200BO-112186/1), the Swiss Heart Foundation, the Fonds Scientifique Cardiovasculaire de Fribourg, and the Swiss Foundation for Nutrition Research (Project 351).

\section{REFERENCES}

1. Baller D, Bretschneider HJ, Hellige G. A critical look at currently used indirect indices of myocardial oxygen consumption. Basic Res Cardiol 76: 163-181, 1981.

2. Baron AD, Brechtel G. Insulin differentially regulates systemic and skeletal muscle vascular resistance. Am J Physiol Endocrinol Metab 265: E61-E67, 1993.

3. Bertinieri G, Di Rienzo M, Cavallazzi A, Ferrari AU, Pedotti A, Mancia G. Evaluation of baroreceptor reflex by blood pressure monitoring in unanesthetized cats. Am J Physiol Heart Circ Physiol 254: H377H383, 1988.

4. Bray GA, Nielsen SJ, Popkin BM. Consumption of high-fructose corn syrup in beverages may play a role in the epidemic of obesity. Am J Clin Nutr 79: 537-543, 2004.

5. Brown CM, Barberini L, Dulloo AG, Montani JP. Cardiovascular responses to water drinking: does osmolality play a role? Am J Physiol Regul Integr Comp Physiol 289: R1687-R1692, 2005.

6. Brown CM, Dulloo AG, Montani JP. Water-induced thermogenesis reconsidered: the effects of osmolality and water temperature on energy expenditure after drinking. J Clin Endocrinol Metab 91: 3598-3602, 2006.

7. Brundin T, Branstrom R, Wahren J. Effects of oral vs. iv glucose administration on splanchnic and extrasplanchnic O2 uptake and blood flow. Am J Physiol Endocrinol Metab 271: E496-E504, 1996.

8. Brundin T, Wahren J. Whole body and splanchnic oxygen consumption and blood flow after oral ingestion of fructose or glucose. Am J Physiol Endocrinol Metab 264: E504-E513, 1993.

9. Bunag RD, Tomita T, Sasaki S. Chronic sucrose ingestion induces mild hypertension and tachycardia in rats. Hypertension 5: 218-225, 1983.

10. Ceriello A, Taboga C, Tonutti L, Quagliaro L, Piconi L, Bais B, Da Ros R, Motz E. Evidence for an independent and cumulative effect of postprandial hypertriglyceridemia and hyperglycemia on endothelial dysfunction and oxidative stress generation: effects of short- and long-term simvastatin treatment. Circulation 106: 1211-1218, 2002.

11. Chong MF, Fielding BA, Frayn KN. Mechanisms for the acute effect of fructose on postprandial lipemia. Am J Clin Nutr 85: 1511-1520, 2007.

12. Crapo PA, Kolterman OG, Olefsky JM. Effects of oral fructose in normal, diabetic, and impaired glucose tolerance subjects. Diabetes Care 3: $575-582,1980$.

13. Frayn KN. Calculation of substrate oxidation rates in vivo from gaseous exchange. J Appl Physiol 55: 628-634, 1983.

14. Fugmann A, Millgard J, Sarabi M, Berne C, Lind L. Central and peripheral haemodynamic effects of hyperglycaemia, hyperinsulinaemia, hyperlipidaemia or a mixed meal. Clin Sci (Lond) 105: 715-721, 2003.

15. Jansen RW, Penterman BJ, van Lier HJ, Hoefnagels WH. Blood pressure reduction after oral glucose loading and its relation to age, blood pressure and insulin. Am J Cardiol 60: 1087-1091, 1987.

16. Kamide K, Rakugi H, Higaki J, Okamura A, Nagai M, Moriguchi K, Ohishi M, Satoh N, Tuck ML, Ogihara T. The renin-angiotensin and adrenergic nervous system in cardiac hypertrophy in fructose-fed rats. Am J Hypertens 15: 66-71, 2002.

17. Laurent D, Bolene-Williams C, Williams FL, Katz LN. Effects of heart rate on coronary flow and cardiac oxygen consumption. Am J Physiol 185: 355-364, 1956.
18. Malliani A, Pagani M, Lombardi F, Cerutti S. Cardiovascular neural regulation explored in the frequency domain. Circulation 84: 482-492, 1991.

19. Malpas SC. Neural influences on cardiovascular variability: possibilities and pitfalls. Am J Physiol Heart Circ Physiol 282: H6-H20, 2002.

20. Martinez FJ, Rizza RA, Romero JC. High-fructose feeding elicits insulin resistance, hyperinsulinism, and hypertension in normal mongrel dogs. Hypertension 23: 456-463, 1994.

21. Miller AW, Sims JJ, Canavan A, Hsu T, Ujhelyi MR. Impaired vagal reflex activity in insulin-resistant rats. J Cardiovasc Pharmacol 33: 698702, 1999.

22. Muniyappa R, Montagnani M, Koh KK, Quon MJ. Cardiovascular actions of insulin. Endocr Rev 28: 463-491, 2007.

23. Murphy SP, Johnson RK. The scientific basis of recent US guidance on sugars intake. Am J Clin Nutr 78: 827S-833S, 2003.

24. Paolisso G, Manzella D, Ferrara N, Gambardella A, Abete P, Tagliamonte MR, De Lucia D, Furgi G, Picone C, Gentile S, Rengo F, Varricchio M. Glucose ingestion affects cardiac ANS in healthy subjects with different amounts of body fat. Am J Physiol Endocrinol Metab 273: E471-E478, 1997.

25. Parati G, Pomidossi G, Albini F, Malaspina D, Mancia G. Relationship of 24-hour blood pressure mean and variability to severity of target-organ damage in hypertension. J Hypertens 5: 93-98, 1987.

26. Parlow J, Viale JP, Annat G, Hughson R, Quintin L. Spontaneous cardiac baroreflex in humans. Comparison with drug-induced responses. Hypertension 25: 1058-1068, 1995.

27. Popkin BM, Nielsen SJ. The sweetening of the world's diet. Obes Res 11: 1325-1332, 2003.

28. Pozza G, Galansino G, Hoffeld H, Foa PP. Stimulation of insulin output by monosaccharides and monosaccharide derivatives. Am J Physiol 192: 497-500, 1958.

29. Sanchez-Lozada LG, Tapia E, Jimenez A, Bautista P, Cristobal M, Nepomuceno T, Soto V, Avila-Casado C, Nakagawa T, Johnson RJ, Herrera-Acosta J, Franco M. Fructose-induced metabolic syndrome is associated with glomerular hypertension and renal microvascular damage in rats. Am J Physiol Renal Physiol 292: F423-F429, 2007.

30. Sawchenko PE, Friedman MI. Sensory functions of the liver-a review. Am J Physiol Regul Integr Comp Physiol 236: R5-R20, 1979.

31. Schwarz JM, Acheson KJ, Tappy L, Piolino V, Muller MJ, Felber JP, Jequier E. Thermogenesis and fructose metabolism in humans. Am J Physiol Endocrinol Metab 262: E591-E598, 1992.

32. Tappy L, Randin JP, Felber JP, Chiolero R, Simonson DC, Jequier E, DeFronzo RA. Comparison of thermogenic effect of fructose and glucose in normal humans. Am J Physiol Endocrinol Metab 250: E718-E724, 1986.

33. Task Force of the European Society of Cardiology, and the North American Society of Pacing and Electrophysiology. Heart rate variability: standards of measurement, physiological interpretation and clinical use. Circulation 93: 1043-1065, 1996.

34. Teff KL, Elliott SS, Tschop M, Kieffer TJ, Rader D, Heiman M, Townsend RR, Keim NL, D'Alessio D, Havel PJ. Dietary fructose reduces circulating insulin and leptin, attenuates postprandial suppression of ghrelin, and increases triglycerides in women. J Clin Endocrinol Metab 89: 2963-2972, 2004.

35. Visvanathan R, Chen R, Garcia M, Horowitz M, Chapman I. The effects of drinks made from simple sugars on blood pressure in healthy older people. Br J Nutr 93: 575-579, 2005.

36. Vogel RA, Corretti MC, Plotnick GD. Effect of a single high-fat meal on endothelial function in healthy subjects. Am J Cardiol 79: 350-354, 1997.

37. Vollenweider P, Tappy L, Randin D, Schneiter P, Jequier E, Nicod P, Scherrer U. Differential effects of hyperinsulinemia and carbohydrate metabolism on sympathetic nerve activity and muscle blood flow in humans. J Clin Invest 92: 147-154, 1993.

38. Weir JB. New methods for calculating metabolic rate with special reference to protein metabolism. $J$ Physiol 109: 1-9, 1949. 